\title{
Comunidade, globalização e educação: um ensaio sobre a desconversão do social'
}

Pablo de Marinis *

Resumo: Junto com algumas teorias sociológicas clássicas produzidas entre os séculos XIX eXX, o texto começa problematizando a constituição histórica do "social estatal-nacional". Analisamse os processos em curso que marcam sua "desconversão". As palavras-chave desses processos são "comunidade" e "globalização". A partir desta premissa teórica, conclui-se, fazendo uma reflexão sobre algumas das realidades sócio-educacionais do presente.

Palavras-chave: comunidade; globalização; políticas educacionais

Community, globalization and education: an essay about deconverting the social instance

Abstract: Taking some of the classical sociological theories produced between the 19th and the 20th centuries, the text starts with the questioning of the historical constitution of a construct named "lo social-estato-nacional". The current processes which evidence its "desconversión" are then analyzed. The key words of these processes are "community" and "globalization". With a basis on this theoretical premise, conclusions are drawn on some of the socio-educational realities of the present times.

Key words: community; globalization; educational policies.

* Doutor em Filosofia pela Universität Hamburg, Alemanha, 1997. Professor de Teoria Sociológica na cátedra de Sociologia na Facultad de Ciencias Sociales da Universidad de Buenos Aires (Flacso). Professor do Mestrado em Ciências Sociais, com orientação em Educação, e do Doutorado em Ciências Sociais na Flacso, Argentina. Investigador do CONICET, com sede de trabalho no Instituto de Investigaciones Gino Germani da Facultad de Ciencias Sociales de la Universidad de Buenos Aires. Algumas de suas publicações: "Gobierno, gubernamentalidad, Foucault y los anglofoucaultianos (Un ensayo sobre la racionalidad política del neoliberalismo)". In: RAMOS TORRE, Ramón e GARCÍA SELGAS, Fernando (Org.). Globalización, riesgo, reflexividad. Tres temas de la teoría social contemporánea. Madrid: Centro de Investigaciones Sociológicas, 1999. pp.73-103. Überwachen und Ausschließen. Machtinterventionen in urbanen Räumen der Kontrollgesellschaft. Pfaffenweiler, Alemanha: Centaurus Verlagsgesellschaft, 2000. "I 6 comentarios sobre la(s) sociología(s) y la(s) comunidad(es)". Papeles del CEIC — Centro de Estudios sobre la Identidad Colectiva (CEIC), Universidad del País Vasco, España, n. I5, enero, 2005. Disponível em: <http://www.identidadcolectiva.es/pdf/I5.pdf>.pdemarinis@fibertel.com.ar.

I. Tradução: Rosiver Pavan (rosiver.pavan@gmail.com). Revisão técnica: Nora Rut Krawczyk 


\section{Introdução}

Muitos dos discursos políticos e científico-sociais vigentes mantêm-se presos a esquemas analíticos que envelheceram irremediavelmente. À luz das importantes transformações das últimas três décadas é ainda sustentável uma contundente divisão analítica entre Estado e Sociedade? Pode caracterizar-se o Estado atual como uma fábrica central de governabilidade, ou mudaram suas funçōes e as características que assumem as relações que estabelece com outros atores? A sociedade possui ainda as características do todo orgânico que alguns dos sociólogos clássicos do final do século XIX e início do XX souberam caracterizar? Se houve recentemente mudanças qualitativas importantes, que formas assumiram e como impactaram as formas de governar o social? E, focalizando nos assuntos trabalhados neste dossiê: como influíram sobre as formas de caracterizar e governar os sistemas educacionais?

Todas estas perguntas são de grande alcance, e os problemas que colocam deveriam ser explorados em âmbitos empíricos delimitados. Aqui se desenvolverão apenas algumas reflexões teóricas de caráter geral que podem servir para sustentar essa tarefa.

Depois desta introdução, na qual se apresentam as perguntas centrais do trabalho, no segundo item será explicado o processo histórico e social que conduziu à construção do social estatal-nacional, recuperando algumas teorizações sociológicas clássicas produzidas entre os séculos XIX e XX que caracterizaram aquele processo por meio de recursos conceituais, entre outros, o da fórmula comunidade-sociedade.

No terceiro item serão apresentados alguns delineamentos teóricos para caracterizar os processos que estão na base da desconversão do social estatalnacional, em curso atualmente. Duas serão as palavras chaves: globalização (3.1) e comunidade (3.2).

Ao final, serão apresentadas algumas conclusões fragmentárias e tentativas, a partir do desdobramento dos desenvolvimentos teóricos anteriores, para produzir uma reflexão sobre algumas das realidades sócio-educativas do presente.

\section{A era do social estatal-nacional}

A modernidade ocidental surgiu marcada por imensas e vertiginosas transformaçôes. Giddens (1993, p. 18) afirma que as formas de vida introduzidas pela modernidade "arrasaram de maneira sem precedentes todas as modalidades tradicionais da ordem social", acelerando o ritmo e expandindo o âmbito da mudança. Foram dois os principais conceitos cunhados para explicar estas importantes mudanças: revolução industrial e revolução democrática. 
Sob o primeiro termo englobaram-se, sobretudo, as transformações da economia, a consolidação do capitalismo como modo de produção dominante, os processos de urbanização, o predomínio dos mecanismos de mercado e a generalização do trabalho assalariado.

Por sua vez, a revolução democrática não é caracterizável de maneira tão homogênea, dado que sob este conceito incluíram-se a revolução inglesa do século XVII; a francesa, de 1789; a Declaração da Independência dos Estados Unidos, em 1776; e, inclusive, os processos de independência das nações latino-americanas do século XIX. Em qualquer desses casos, a revolução democrática implicou um grande impulso para a constituição de alguns regimes políticos fundados na soberania popular.

A ciência política moderna (pelo menos a partir do contratualismo), a economia política clássica, o marxismo e a sociologia, aproximadamente nessa ordem cronológica, foram responsáveis pela maior parte dos conceitos com os quais ainda hoje temos que trabalhar. Neste trabalho, serão focalizados os desenvolvimentos teóricos realizados pela sociologia.

Para explicar os processos que deram passagem à modernidade ocidental, alguns membros da segunda geração de pais fundadores da sociologia ${ }^{2}$ outorgaram centralidade analítica ao par conceitual Gemeinschaft - Gesellschaft, comunidade - sociedade. Tendo esses conceitos ou outros similares em mãos, sociólogos como Ferdinand Tönnies, Max Weber, Emile Durkheim e Georg Simmel, ao mesmo tempo, propuseram-se vários objetivos ${ }^{3}$. De um lado, captar os traços mais salientes da mutação histórica à qual estavam assistindo em sua época, recolhendo evidências acerca das ambivalentes conseqüências das duas revoluçõos acima mencionadas. De outro, construir tipos ideais de relações sociais para descrever formas particulares de agregação de indivíduos e grupos, no mesmo diapasão da vocação científico-empírica da disciplina nascente.

Para além das particularidades de cada autor, observa-se em todos eles um esforço por captar os complexos perfis da mutação histórica fundamental que arrasou a sociedade tradicional e abriu passagem à sociedade moderna. Dessa forma, comunidade e sociedade apareceram como tipos históricos, como descritores dos perfis peculiares do que estava deixando de ser e do que estava começando a se constituir. De um lado, o natural, o orgânico, a vida em comum sobre a base de origens e sentimentos compartilhados. De outro lado, a

2. Faz-se com isso referência à geração que atuou nos finais do século $X I X$ e começos do $X X$.

3. Estes autores aparecerão aqui apresentando uma posição compartilhada, porém, é óbvio que também existem diferenças significativas entre eles. Para aprofundá-las, veja-se, por exemplo, de Marinis (2005a; 2006) e a bibliografia citada nesses trabalhos. 
racionalidade, a reflexividade, o individualismo, a artificialidade, os mecanismos impessoais, os contratos. O primeiro pode ser associado imediatamente à vida camponesa, à aldeia medieval, aos laços da família ampliada, em suma, às ordens tradicionais. O segundo pode ser vinculado ao anonimato e à impessoalidade das grandes urbes, ao industrialismo, em suma, aos principais traços da vida social moderna ${ }^{4}$.

Além desses tipos históricos, a sociologia cunhou também alguns tipos ideais de comunidade e sociedade para identificar as modalidades que pode assumir a agregação coletiva. Tal é o caso de Max Weber. Para o caso da comunidade, Weber realçou o sentimento subjetivo de pertencimento comum por parte dos membros de um coletivo; para o segundo caso, sublinhou o maior peso que tem o ajuste de interesses motivados racionalmente, valorativamente e/ou com relação aos fins.

Para além de todos esses tecnicismos sociológicos, a respeito dos quais muito mais foi dito e ainda se poderia dizer ${ }^{5}$, encontra-se uma preocupação compartilhada por diferentes fraçōes das classes dominantes da época e assumida como desafio teórico-político pelos próprios sociólogos. Muito resumidamente, temia-se que a rápida generalização das refrigeradas relaçôes que a Gesellschaft vinha trazendo consigo - por meio da racionalização do domínio político, da burocratização das instituições, da formalização e despersonalização das relações sociais, da autonomização das esferas funcionais, etc. — terminasse deglutindo, subsumindo, arrasando todos os contextos cálidos, tranqüilos, de relações cara a cara, de intensa emotividade, âmbitos seguros e familiares da interação e das redes de proteção próxima. Portanto, temia-se a destruição total da comunidade pela sociedade com as conseqüências, consideradas por eles perniciosas, que isso podia acarretar, pois, se na comunidade reinava uma ordem e existiam garantias de identidade para seus membros, sob condiçôes de sociedade, ambas as coisas poderiam ser colocadas em risco.

Para esses sociólogos, a irrupção da sociedade trouxe consigo vários avanços: eficiência organizacional, produtividade econômica, racionalidade formal no exercício do poder, espaço livre para o uso da razão, etc. A velha comunidade

4. As coisas não são tão simples nem tão polarmente opostas, nem sequer para um autor como Tönnies, acusado injustamente de nostálgico em relação à ordem pré-moderna (cf. Nisbet, 1996). Para ele, por exemplo, as cidades modernas ainda admitem algum espaço para as comunidades, e o Estado (claro exemplo do pólo da sociedade) não deixa de apelar a sentimentos nacionais na hora de convocar seus cidadãos a matar os inimigos da Nação (óbvio expoente do pólo comunitário).

5. Estas questões estão sendo analisadas num projeto de pesquisa coordenado pelo autor deste trabalho, desenvolvido no Instituto de Pesquisas "Gino Germani" da Universidade de Buenos Aires, que tem, entre seus objetivos, a exploração reconstrutiva do pensamento dos autores clássicos da sociologia em torno do tema da "comunidade". 
dava certezas, construía identidades estáveis, porém era tremendamente opressiva e, no aspecto crítico da comunidade tradicional, esses autores mostravam sua sensibilidade modernizante. Por tudo isso, eles ficaram muito longe de pretender a simples reabilitação da velha Gemeinschaft.

Contudo, também compreenderam que as novas oportunidades vinham infestadas de riscos. A racionalização do domínio público havia acabado com as hierarquias de base estamental, mas poderia conduzir a novas formas de despotismo e demagogia; a burocratização do Estado, dos partidos e das empresas, embora tivesse provado ser o melhor instrumento para a administração de coisas e corpos, poderia gerar novas formas de servidão e reforçar as grades da gaiola de ferro. A crescente formalização e despersonalização das relaçôes sociais e o individualismo haviam arrasado o opressivo mundo dos status adscritos, porém poderiam intensificar-se o egoísmo, a solidão e o anonimato. A urbanização era a condição do progresso, mas por sua vez poderia converter-se no fermento da sedição política, o crime, as epidemias, o suicídio; a divisão do trabalho social sob condições de solidariedade orgânica havia demonstrado sua maior eficácia e eficiência, porém poderia assumir formas patológicas; as relações sociais próprias do capitalismo industrial haviam posto por terra um mundo produtivo atrasado, porém poderiam levar a intoleráveis condiçôes de exploração, alienação e fetichismo; a laicização e o racionalismo haviam acabado com as superstiçôes religiosas, mas poderiam tornar intolerável a existência dos indivíduos em um mundo desencantado e esvaziado de sentidos transcendentais, etc. Em suma, as antinomias da sociedade moderna abriam passagem a tudo isso de uma vez: a concretização de formas avançadas de convivência coletiva e de realização individual e pessoal, porém a possibilidade de recaída na dissolução, no caos e na desintegração sociomoral ${ }^{6}$.

Assim como o capitalismo e a industrialização deram uma estocada de morte à Gemeinschaft no que diz respeito às bases materiais, os direitos civis e políticos e - já nos finais de século XIX — os partidos políticos, os sindicatos de massas e a educação pública fizeram o mesmo no que se refere a suas dimensões políticas, sociais e culturais.

Além das mencionadas revoluções industrial e democrática, em processos a elas colaterais - e, inclusive, inserindo-se propriamente como parte delas poder-se-iam mencionar muitos outros fenômenos que marcaram essa grande transformação que se operou ao longo de todo o século XIX. Aqui haveria de se mencionar a crescente e vertiginosa urbanização. Outro fenômeno importante

6. A mistura de afirmações de marca marxista, weberiana, simmeliana e durkheimiana é feita com a finalidade de localizar uma problemática compartilhada, para além das diferenças de ênfase e de interesses teórico-políticos. 
foi a burocratização do Estado e das organizações de todo tipo, desde as empresas até os sindicatos, os partidos políticos e as universidades. ${ }^{7}$ Também aquela foi uma época em que os Estados assumiram fortemente, entre suas iniciativas de poder, a invenção ou a promoção de dispositivos de produção homogeneizadora e normalizadora de cidadãos. Sob esta rubrica, poderiam ser mencionados dispositivos tais como: o serviço militar obrigatório, os sistemas de escolarização pública e de massa, as instituiçōes criadas para enfrentar os problemas derivados da questão social, os aparatos punitivos e, também, a seu modo, a família nuclear ${ }^{8}$.

O surgimento de todos estes dispositivos obedece a múltiplas causas. Devido a isso, embora se tenha sublinhado aqui a centralidade do Estado em todos esses processos, a análise não deveria se reduzir exclusivamente a ele. Muitas destas iniciativas (por exemplo, as vinculadas à educação) articularam de forma complexa as ações do Estado e as de diversos agentes não estatais, mas é inegável a centralidade do Estado em todo esse processo.

Por exemplo, no que tange especificamente à constituição dos sistemas educacionais nacionais, Ramírez e Boli (1999) sustentam que o desenvolvimento dos sistemas educacionais nacionais obedeceu a causas múltiplas que não se podem reduzir a uma mera resposta às necessidades de força de trabalho da economia industrial, nem tampouco a uma simples maneira de tratar os conflitos de classe. Em síntese, esses autores afirmam que os diversos estados europeus embarcaram na empresa de conformar uma política nacional unificada e, graças a essa política, os indivíduos conseguiram uma identificação com a nação e envolveram-se em projetos nacionais.

Em poucas palavras, essa época pode ser denominada como a da "invenção do social". Em especial, considerando-se os diversos dispositivos acima mencionados, dever-se-ia propriamente falar-se do social estatal-nacional, uma modalidade de articulação entre Estado-Nação e sociedade instituída lentamente ao longo do século XIX.

No século XX, essa articulação conseguiu consolidar-se efetivamente, mas experimentou complexas vicissitudes. Assim, a era da governabilidade liberal, concomitantemente ao surgimento de o social, foi lentamente cedendo passagem a outras novas racionalidades de governo que ficaram conhecidas como estado de bem-estar ou estado benfeitor, keynesianismo, etc. Embora houvesse

7. Urbanização e burocratização são palavras-chave de rotina que atravessam boa parte da obra de Simmel e de Weber, respectivamente.

8. Sobre estes últimos pontos são referências inelidíveis os textos de Foucault em torno dos conceitos de sociedade disciplinar e biopoder (1976; 1987; 1996; 2000; 2006).

9. A expressão "invenção do social" é usada no sentido que lhe outorgou Donzelot nos finais dos anos 1980 (2007). 
significativas diferenças regionais e temporais, o Estado de Bem-Estar tornouse uma realidade evidente em boa parte do mundo ocidental, inclusive, também, em alguns países latino-americanos, em versões peculiares que, embora como tendência, compartilharam traços importantes com os casos da Europa e dos Estados Unidos (peronismo na Argentina, varguismo no Brasil, cardenismo no México, etc.), participando dessa leva de marca keynesiana característica das décadas posteriores à crise dos anos 1930. Dentre esses traços destacam-se a centralidade do Estado nas intervenções de poder, a expansão concomitante de algumas noções de "cidadania social" ${ }^{10}$, a consolidação do estatuto do trabalho assalariado ${ }^{11}$, etc.

A seguir, tentar-se-á demonstrar que a história acabou brincando com aqueles sociólogos clássicos. Muitos de seus temores resultaram, a posteriori, ser parcialmente exagerados.

Primeiro: como já se disse, umas poucas décadas depois de que foram escritos aqueles textos fundacionais da disciplina, mais que uma dissolução da comunidade e uma inexorável destruição de toda a ordem, consolidou-se melhor outro tipo de ordem, marcado pelo estado de bem-estar ${ }^{12}$. Dentro do congelador da cidadania social, ficaram afiadas, ao menos por um tempo, as mais pungentes arestas do conflito social do período anterior. Assim, o social continuou certamente vivo algumas décadas depois de sua invenção.

Segundo: há aproximadamente trinta anos, esse poderoso edifício do social vem experimentando uma intensa corrosão de seus fundamentos. Praticamente todos os dispositivos institucionais que se inventaram ou consolidaram sob o signo de o social estão atravessando uma crise profunda, da família até o trabalho assalariado, passando pelo sistema educacional e pelos sistemas de proteção social.

São dois os processos que estão na base da desconversão do social estatalnacional e que serão analisados neste trabalho. De um lado, a tão célebre globalização. De outro lado, a comunidade que não desapareceu como temiam os sociólogos clássicos, mas, ao contrário, está experimentando um impressionante renascimento nos últimos tempos. Cabe também antecipar que não é exatamente a velha comunidade pré-moderna a que está reaparecendo, mas algumas comunidades "pós-sociais" 13 com perfis inovadores. Estes temas serão tratados no próximo item.

10. Veja-se, por exemplo, Castel (2004) sobre a sucessão histórica de tipos de cidadania.

I I. Sobre a história do trabalho assalariado, pode se consultar Castel ( 1997).

12. O qual, por sua vez, também se revelaria como uma ordem transitória, como se verá na continuação.

13. O conceito de pós-socialidade é desenvolvido em de Marinis (2000). 
A desconversão do social estatal-nacional: globalização e comunidade na era neoliberal

Nesta seção, caracterizar-se-á a desconversão do social estatal-nacional atualmente em curso. $\mathrm{O}$ foco será colocado sobre alguns processos de transformação da relação Estado-sociedade ou, como o temos chamado antes, do social estatal-nacional. Os processos implicados tanto na reinvenção da comunidade (que operam de baixo e de dentro) como na globalização (que operam de cima e de fora) parecem estar na base de um fenômeno marcado pela desconversão, pela desvalorização, pela corrosão ou pela ressignificação do poder e da soberania dos Estados nacionais. A teoria social e política deve necessariamente passar recibo disso: o esquema analítico Estado-sociedade ou público-privado, que já tem um par de séculos de vigência, ressente-se significativamente ante as novas evidências que a realidade atual aponta. Isto exige revisar, renovar e reconstituir o arsenal conceitual de que dispomos para nossas pesquisas.

Poder-se-ia utilizar uma palavra-chave para caracterizar a situação atual, também chamada neoliberal: a economização dos meios de governo que o Estado efetua crescentemente. Assim, mais que uma separação contundente entre duas entidades (Estado versus Sociedade), conforma-se em realidade uma complexa rede em cujo marco se planificam, desenham, executam e avaliam políticas, planos e programas de governo. Essa densa estrutura está integrada tanto por dependências formalmente estatais como por entidades subestatais e supraestatais, Ongs, organismos internacionais, think tanks, meios de comunicação, partidos políticos, organizações sociais e comunitárias de diversos tipos, etc.

Como meio ou também como efeito dessa nova situação, verifica-se uma economia dos meios de governo do Estado. O Estado economiza, racionaliza e otimiza cada vez mais suas energias, aproveitando-se, servindo-se de e apelando à energia dos próprios governados para governá-los melhor. A imagem da economização que aqui se sustenta parece ser muito mais adequada que a convencional menção a retirada, retrocesso, extinção ou desaparição do Estado, habitual em grande parte da bibliografia crítica do neoliberalismo. Economização, pois, remete a um novo formato adelgaçado da atividade estatal, que deve lidar por cima com os processos de globalização e, por baixo, com a explosão de formas particularistas de subpolítica, que às vezes levam o nome de comunidade. Nos tópicos abaixo serão considerados ambos os processos, começando pela globalização.

\section{A desconversão do social estatal-nacional de cima e de fora: a globalização}

A globalização tem estado na fala de todos, especialmente a partir dos anos 1990. Por isso, há disponível uma abundância de definições. Aqui se pretende 
apresentar alguns argumentos para discutir com lugares-comuns recorrentes, muitas vezes enviesados, unilaterais e parcialmente falsos. Entre esses: que a globalização é um fenômeno recente e preponderantemente econômico; que arrasa totalmente com o poder e a soberania dos Estados nacionais e se desenvolve a expensas deles, sem distinção de Estados nem de âmbitos de atividade dentro deles; que é um processo quase natural, como se carecesse de sujeito, e conduz a efeitos necessariamente homogeneizadores e desdiferenciadores das diversas regiões do mundo. Sem dúvida, há algo certo em tudo isso, porém, estas afirmaçôes deveriam ser matizadas, e seu alcance investigado empiricamente, atendendo às particularidades nacionais e regionais envolvidas.

Primeiro, há que dizer que o capitalismo foi desde seus primórdios um fenômeno intrinsecamente globalizador, como bem o soube ver Marx prematuramente $^{14}$. A globalização não é então um fenômeno necessariamente recente, ainda que alguns processos tenham intensificado seu ritmo nas últimas décadas. É possível identificar etapas na globalização, e a atual combina tanto elementos de continuidade como de ruptura em relação a momentos anteriores.

Vários exemplos reforçam essa afirmação: a expansão da economia global durante os anos 1990, logo após as crises dos anos 70 e 80, a derrocada do socialismo real entre 1989 e 1991; o crescimento dos Estados Tigres e o novo papel da China, que ofende o significado histórico do Terceiro Mundo; a ampliação das desigualdades Norte-Sul, o mesmo de outras desigualdades regionais e intranacionais; a consolidação relativamente pacífica da União Européia, mesmo com a presença em seu seio de situaçōes conflitivas (terrorismo, fortes desvalorizações do status de cidadania para jovens, trabalhadores migrantes e refugiados, etc.); a Guerra do Golfo que deu passagem a uma noção de guerra realmente global, afirmando o poder dos Estados Unidos como garantidor da nova ordem mundial; o ataque às Torres Gêmeas de New York, que traçou novos limites entre conceitos tais como segurança interior e segurança exterior. Nesses exemplos podem ver-se tanto expansóes quantitativas como modificações qualitativas de desenvolvimentos anteriores.

A globalização é, além disso, um fenômeno multidimensional. As dimensões econômicas sem dúvida dão o tom das transformações, porém outras dimensões (sociais, políticas, culturais, epistemológicas, etc.) têm seu peso próprio. De fato, é característico da fase atual da globalização o papel que ocupa a produção das empresas transnacionais em um contexto dominado pelo sistema financeiro; além disso, deve mencionar-se a implementação de processos de produção fle-

14. "Instigada pela necessidade de dar cada vez mais saída a seus produtos, a burguesia percorre o mundo inteiro. Necessita aninhar-se em todas as partes, estabelecer-se em todas as partes, criar vínculos em todas as partes. Mediante a exploração do mercado mundial, a burguesia deu um caráter cosmopolita à produção e ao consumo de todos os países" (I 985, 39). 
xíveis e multilocais, a desregulação das economias nacionais, a preeminência dos organismos financeiros multilaterais, etc. (Santos, 2003, pp. 170-173). Esses processos desenvolveram-se em todo o mundo, mas seus efeitos foram diferentes conforme os países e as regióes no sistema mundial. Parece impressionante a coincidência das orientações das políticas econômicas nacionais - ou das exigências que se desferem sobre elas - na base do consenso neoliberal. Assim, também segundo Santos, observa-se em toda parte uma abertura ao mercado mundial; políticas monetárias e fiscais orientadas à redução da dívida pública e ao combate à inflação; uma privatização do setor empresarial do Estado; uma redução do peso das políticas sociais no gasto público; e uma redução destas a medidas compensatórias dirigidas aos setores mais pobres.

Ao referirem-se aos aspectos sociais da globalização, diversos autores dão conta da emergência de uma nova estrutura de classes, na qual se destaca uma classe capitalista transnacional, cujo campo de reprodução é o globo como tal (Santos, 2003, p. 173). Nas últimas décadas, além disso, produziu-se um aprofundamento da desigualdade na distribuição da renda: um quarto da população mundial vive em condições de pobreza absoluta. Também se pode mencionar a liberalização do mercado de trabalho e a redução dos direitos trabalhistas, que atinge somente os assalariados; além disso, também se vem expandindo a proporção de desempregados e marginalizados. Em suma, assistimos a uma "crise do contrato social" (Santos, 2005, p. 21 e seg.) em que os mecanismos de exclusão ultrapassam os de inclusão.

No que tange aos aspectos políticos da globalização, houve recentemente mudanças relevantes no sistema interestatal. Os Estados hegemônicos e os organismos internacionais que eles controlam reduziram a soberania dos países semiperiféricos e periféricos. Quijano (2000) chama a este conglomerado "Bloco Imperial Mundial", integrado pelos estados hegemônicos, pelos organismos de controle da violência (como a Otan) e das finanças internacionais (Banco Mundial, FMI, BID, etc.) e pelas grandes corporações globais. Este bloco impõe suas decisóes sem haver sido eleito ou designado pelos demais estados do mundo, constituindo-se uma espécie de "autoridade pública mundial" (2000, p. 9).

De outro lado, também tiveram lugar vários acordos políticos interestatais (Nafta, Mercosul, União Européia, etc.). Estes dois processos ("Bloco Imperial Mundial" e espaços de integração regional) têm impactos diferentes conforme os países, mas, devido a eles, todos os Estados-Nação parecem em alguma medida haver perdido sua centralidade tradicional como unidade privilegiada de iniciativa econômica, social e política (Santos, 2003, p. 178). Assim, acaba afetada a capacidade dos Estados para conduzir ou controlar fluxos de pessoas, bens, capitais ou idéias da mesma forma que haviam conseguido fazê-lo no passado. 
Outra vez, impõem-se as relativizações: a capacidade estatal não se vê reduzida da mesma forma em todos os países, conforme sejam hegemônicos, semiperiféricos ou periféricos. Também se deve afirmar que esse impacto não se dá da mesma forma em todos os âmbitos de atividade. Em referência aos países latino-americanos, Gudynas (2005) mostra como um Estado, inclusive dentro de um mesmo país, pode combinar ao mesmo tempo uma presença muito débil - incapaz de garantir mínimos direitos cidadãos - e intervenções muito enérgicas para proteger empreendimentos orientados à exportação e gerenciados por empresas estrangeiras. Essa tendencial perda de centralidade do Estado é outro dos aspectos que claramente introduzem uma descontinuidade em relação ao passado, dado que, desde a fundação do sistema interestatal moderno, há quatro séculos, o poder do Estado não tinha feito outra coisa mais que se expandir.

As dimensões culturais da globalização parecem ser ainda mais esquivas para sua análise. Outra vez seguindo Santos (3003, p. 187 e seg.), é possível perguntar se o que se designa como globalização não deveria ser conceituado como "ocidentalização" ou "americanização", pois é evidente que são valores e instituiçôes ocidentais os que vêm se generalizando nas últimas décadas (individualismo, democracia política, racionalidade econômica, direitos humanos, etc.).

Também se poderia refletir se a globalização implica necessariamente homogeneização. Se os aspectos econômicos ("consenso neoliberal") e políticos (perda de centralidade do ator estatal) apresentam forte unidade de efeitos para além dos casos nacionais, no campo cultural o cenário parece ser muito mais complexo. Pode se falar da recente emergência de uma cultura global? Pelo menos desde o século XVI, a ciência, a economia, a religião e a política européias alcançaram um nível de homogeneidade entre as diferentes culturas nacionais. Também se pergunta Santos se nos últimos tempos não surgiram algumas formas culturais originalmente transnacionais ou cujas origens nacionais apareçam como relativamente irrelevantes (2003, p. 189). Ainda mais, não é a promoção de uma cultura global um dos traços característicos do projeto ocidental moderno e não tanto um fenômeno de recente aparição?

Para responder a estas perguntas, requerem-se investigações detalhadas a partir de uma base empírica definida. Somente se pretendeu sublinhar o contraste entre essa espécie de isoformismo institucional no econômico e no político e como ele pode coexistir muito bem com uma intensificação da "afirmação das diferenças e do particularismo" (Santos, 2003, p. 188) no plano cultural.

Pois, mesmo que a globalização globalize, englobe e submeta entidades e acontecimentos de níveis muito diferentes, ela é uma impressionante produtora de diferenças que sempre se expressam na esfera local. Não seria concei- 
tualmente correto falar da existência de uma só globalização, como um processo único e homogêneo, mas de globalizações, no plural, que podem ser caracterizadas conforme os diferentes atores e interesses que as impulsionam; o que em cada caso se globaliza; e que tipo de relações estabelecem.

Assim, a globalização está distante de ser um fenômeno "linear, monolítico e inequívoco"; não se trata de um processo espontâneo, automático, inelutável e irreversível que se intensifica e avança segundo uma lógica própria (Santos, 2003, p. 192). Na posição que aqui se defende, a globalização é efetivamente produzida e, em sua base, há "dispositivos ideológicos e políticos dotados de intencionalidades específicas" (ibidem).

As ciências sociais enfrentam-se faz algumas décadas com um desafio epistemológico novo: tendo construído suas ferramentas básicas sob as condições de uma época de sociedades nacionais, vêem-se confrontadas com o desafio de pensar uma sociedade global. Assim, na falta de conceitos precisos, costuma-se fazer uso de uma série de metáforas, tais como a aldeia global, a fábrica global, a torre de Babel, a nave espacial, etc. Ianni (1996, p. 4) desenvolve uma análise a respeito destas e outras metáforas, sustentando que elas "parecem florescer quando os modos de ser, atuar, pensar e fabular mais ou menos sedimentados se sentem comovidos" 15 .

A metáfora da aldeia global pretende dar conta de uma espécie de apequenamento do globo pela mão da surpreendente transferência de elementos visuais, sonoros, informaçôes. E fornece a imagem de que estariam em curso "a harmonização e a homogeneização progressivas" (Ianni, 1996, p. 5). Talvez haja alguma verdade em tudo isso. Cadeias televisivas, agências de notícias, a indústria do entretenimento, etc. evidenciam que estamos enlaçados em alguns níveis transnacionais sem precedentes. Contudo, sem dúvida, a quarta parte da humanidade que vive com menos de dois dólares por dia participa bastante pouco, defeituosamente ${ }^{16}$ ou nada desses consumos culturais globais.

Ao introduzir relativizaçôes, pode-se reconhecer que "não há tal coisa como a globalização, pois não há forma pela qual algum padrão de poder possa ser de todo homogêneo, sistêmico, mecânico ou orgânico" (Quijano, 2000, p. 19). O mesmo afirma Santos, para quem a globalização é um "processo por meio do qual uma condição ou instância local consegue estender seu raio de influência ao longo do globo e, ao desenvolver esta ação, desenvolve a capacidade de designar como local a instância ou condição social com a qual compete" (Santos, 2003, p. 86). Dado que há muitas formas distintas de realizar isso, Santos

15. Ver também lanni (1998).

16. Parecem interessantes as referências de Bauman (2000) a respeito dos pobres como "consumidores defeituosos". 
prefere falar de "globalizações", no plural, enfatizando justamente o caráter conflitivo que elas têm (em cada uma delas há "vencedores" e "vencidos"), aí sublinhando o caráter hegemônico ou contra-hegemônico que podem assumir.

Em qualquer caso, é importante reiterar que não se está fazendo meramente referência a processos nos quais o Estado é uma mera vítima passiva de fenômenos que escapam de seu controle. Nisso, é necessário estabelecer novamente especificaçôes. De uma perspectiva latino-americana, Lander fala inclusive do "mito da diminuição do papel do Estado na sociedade global contemporânea" (2002, p. 60), um mito que pode estar cumprindo um papel ideológico de acobertamento de diferenças. Embora

$$
\begin{aligned}
& \text { muitas das funções historicamente associadas à idéia de Esta- } \\
& \text { do[...] já não operem dentro dos limites dos espaços territoriais } \\
& \text { das nações [...], estes processos não significam necessariamente } \\
& \text { uma redução da função estatal, pelo contrário, podem ser ex- } \\
& \text { pressão do deslocamento de funções e atribuições do Estado } \\
& \text { para outras formas estatais supranacionais, sejam regionais ou } \\
& \text { transnacionais. (Lander, 2002, p. 65). }
\end{aligned}
$$

Da mesma forma, para Santos, a adaptação aos requerimentos do contexto internacional global supõe reorganizar massivamente os dispositivos legais e institucionais nacionais. Assim, afirma que essa "desvinculação do Estado não pode ser obtida senão por meio de uma forte intervenção estatal. Paradoxalmente, o Estado deve intervir para deixar de intervir, ou seja, tem que regular sua própria desregulação" (2003, p. 181).

\section{A desconversão do social estatal-nacional de baixo e de dentro: a comunidade}

Cabe agora considerar outros processos que operam de baixo e de dentro do espaço do estado-nacional social e que estão ligados a uma reinvenção da comunidade, atualmente em curso $^{17}$.

Para dizê-lo esquematicamente, a reinvenção da comunidade dá-se por meio de um duplo jogo, em que se observará outra vez que não se trata de pensar o Estado como uma mera vítima passiva de fenômenos que não pode comandar. Assim como a globalização não implica somente um processo inelutável perante o qual os Estados têm necessariamente que se dobrar, globalizando-se, tam-

17. Para isso, foram consultados (embora não exclusivamente) diversos trabalhos da perspectiva teórica que se conhecem como "estudos sobre governamentalidade" (governmentality studies), de inspiração foucaultiana. Veja-se, por exemplo, Rose (1996; 1997; 1999) e Dean (1999). Uma introdução geral e em castelhano a esta perspectiva analítica pode ser encontrada em de Marinis (1999). 
bém nos processos de reinvenção da comunidade podem ocorrer situações similares. Nelas, o Estado pode, por um lado, ser um agente ativo na invenção, constituição ou promoção de comunidades e, em outros casos, deve responder a iniciativas e a demandas de caráter comunitário que estas (ou outras) comunidades lhe fazem de baixo. Em qualquer dos casos, continua sempre estando presente um esforço de economização de meios de governo por parte do Estado, porém não só com a finalidade de retirar-se e desobrigar-se das incumbências que até então lhe eram inerentes, mas para governar mais e melhor ${ }^{18}$.

Assim, tem lugar uma série de iniciativas de um Estado adelgaçado, que constroem comunidades como objeto específico de algumas políticas de governo as quais, longe de manter as velhas tendências universalistas outrora dominantes, tornam-se crescentemente focalizadas e particularistas. O Estado estimula a prudência dos atores (O’Malley, 1996), convoca ao ativismo e à participação e incita à assunção de crescentes e diversificadas responsabilidades por parte das comunidades na criação, definição e gestão de seus próprios destinos e condiçôes de existência. Tudo isso ocorre sem apelar à linguagem da cidadania social que impregnou durante décadas o discurso estatal. A interpelação realiza-se diretamente às comunidades que passam a ser concebidas como as modalidades predominantes de agregação de sujeitos. As novas tecnologias de governo neoliberais tendem a governar "através da comunidade" (Rose, 1966). Inclusive nas atividades mais supostamente sociais que ainda se fazem, como os chamados programas de combate à pobreza, enquanto se chama a romper com a apatia que havia gerado a providencialidade supostamente dadivosa do Estado de Bem-Estar, também se apela às capacidades auto-reguladoras dos indivíduos e das comunidades. Assim, o apelo à participação dos mesmos governados inscreve-se com maiúsculas nesses programas ${ }^{19}$.

Porém, além disso, há outra direção neste processo e é justamente a que procede de baixo. Neste caso, trata-se de indivíduos, agrupamentos, famílias, "tribos" (Maffesoli, 1990) que constroem suas identidades particulares, recortadas e específicas sobre a base de atributos mais ou menos identificáveis e vinculadas, por exemplo, à crença religiosa, à etnia, à orientação sexual, à idade, a alguma forma de consumo cultural, à ocupação ou à profissão, à condição de gênero, à disparidade, à condição de sobrevivente ou de familiar de vítima de violações aos direitos humanos, à inserção em uma localidade, etc. Essas

18. Talvez convenha aclarar que governar "mais" e "melhor" não tem necessariamente a ver com garantir mais firmemente os direitos cidadãos.

19. Trata-se muitas vezes de uma noção muito limitada de participação que costuma apontar apenas à gestão "ativa" e "responsável" de sua própria miséria pelos próprios governados. Cf. de Marinis (2005b), quando reflete criticamente sobre o "participacionismo" no governo da insegurança urbana. 
comunidades organizam suas ocupações vitais, manifestando uma renovada ênfase sobre os contextos micromorais de suas experiências, em detrimento dos cada vez mais distantes, abstratos e vazios conceitos de cidadania social, nacionalidade ou classe social.

Em síntese, o jogo é duplo e revela importantes transformações nas práticas de governo: o Estado já não apela, pois não mais se dirige ampla e ostensivamente ao conjunto da sociedade, ou seja, ao conjunto de cidadãos de uma nação politicamente regulada por ele (como aconteceu até a época do Estado de Bem-Estar), mas dirige-se diretamente a algumas comunidades especificamente recortadas, cuja constituição promove e fortalece e cuja participação em tarefas de governo convoca; do outro lado, as comunidades se (auto) ativam para moldar seus perfis identitários, recriá-los por meio de diversidade de práticas e articular suas demandas a autoridades de diversos tipos.

Assim, novas identidades emergem, ou velhas identidades são fortemente ressignificadas: o vizinho deste ou daquele bairro ou cidade; o consumidor de tais ou quais bens ou serviços; o usuário de algum programa de política pública. Mesmo quando pode continuar sendo invocada, ressente-se ou transtornase a histórica figura do cidadão. Em alguns casos, cai-se ou se é arremessado, simplesmente, em determinada comunidade, sem demasiadas opçóes de escolha ou resistência. Em outros casos, a adesão à comunidade implica operações complexas e construtoras de identificação dos que são como todos e, de tal forma, quando o contexto social mais amplo se torna crescentemente frio, distante, hostil, a comunidade converte-se na forma mais adequada de estar chez $s o i$, um lugar no qual "nunca somos estranhos uns para os outros" (Bauman, 2003, p. 8). Sobretudo nesses casos mais ou menos eletivos, porém também em outros mais ou menos compulsivos, no seio dessas comunidades manifestase uma espécie de reaquecimento dos vínculos, porém, de um tipo fundado no recolhimento da própria territorialidade comunitária, sem referências a totalidades mais amplas de tipo societário nas quais se pode incluir (no caso das comunidades "dos que perderam") ou nas quais se deseja participar (no caso das comunidades "dos que ganharam" ${ }^{20}$.

Retomando os argumentos do segundo item deste trabalho, é possível afirmar a boa saúde da comunidade; nesse sentido, a temerosa suposição dos sociólogos clássicos de que a Gesellschaft pudesse terminar acabando com todos os contextos cálidos de interação próxima, cara a cara e comprometida afetivamente, não se verificou na realidade. A comunidade continua gozando, de fato, de boa saúde.

20. A figura "os que perderam" versus "os que ganharam" é esquemática, porém muito plástica para descrever processos de fragmentação e polarização social como os atuais. (Cf. Svampa, 200 I). 
Porém, tem sentido continuar usando o termo comunidade quando se manifesta tal diversidade empírica de comunidades realmente existentes, ou seja, quando comunidade parece ser o nome que se pode dar a qualquer tipo de agrupamento humano? Continua sendo de utilidade recorrer a este conceito sociológico que, de Tönnies em diante, experimentou tal reviravolta semântica?

Estas interessantes perguntas não serão abordadas neste artigo, porém trata-se de sublinhar a extraordinária persistência da comunidade (ou do desejo ou da necessidade da comunidade) no discurso contemporâneo. Não há praticamente nenhuma forma de ação coletiva que em algum momento não recorra a alguma fórmula de marca comunitária para recrutar novos membros e definir seus planos de ação, desde coletivos de trabalhadores desempregados que reivindicam assistência do Estado até vizinhos de classe média que exigem proteção policial. Não existe quase nenhum programa estatal que prescinda do uso de um vocabulário ou um jargão de marca comunitarista para a definição de seus targets de governo, desde a prevenção comunitária do delito até a atenção à diversidade das diferentes comunidades educativas.

Neste sentido, se o termo vai continuar sendo utilizado, será necessário especificar de qual comunidade se trata. Hoje, como ontem, continua sendo inerente aos membros de uma comunidade essa sensação de estar mais ou menos juntos e avançar (ou retroceder) em caminhos comuns de ação sobre a base de certos traços compartilhados (interesses, gostos, riscos, perigos, inclinações, orientações éticas ou estéticas, afeições, etc.). Em qualquer caso, impõe-se estabelecer precisões sobre as enormes diferenças que, grosso modo, podem se vislumbrar entre as velhas comunidades pré-modernas e as da contemporaneidade, próprias de uma época decididamente pós-social ${ }^{21}$.

As velhas comunidades eram de inscrição compulsiva. Ao contrário, as novas comunidades estão marcadas por uma espécie de vontade de escolha e têm um cheiro à liberdade, à ação pró-ativa ou reativa diante das contingências de um mundo cujos riscos devem ser assumidos individualmente ou no marco de comunidades próximas ${ }^{22}$.

Em segundo lugar, a temporalidade. As velhas comunidades enraizavam-se em um passado ancestral que reenviava a alguns mitos fundacionais e eram consideradas, em princípio, eternas. Porém, as comunidades do presente caracterizam-se por sua não-permanência, por sua evanescência, por ser apenas até novo aviso, até que satisfaçam as necessidades pelas quais surgiram, ou até que percam sua capacidade de manter vivas as motivaçôes de seus membros.

21. Esse inventário de diferenças é desenvolvido com maior datalhamento em de Marinis (2005a).

22. Também é certo que existem muitas comunidades muito parecidas com prisões, mas com territórios a explorar em cursos de ação livres de ataduras. 
Em terceiro lugar, o território. A velha comunidade era a comunidade do território, era-lhe inerente a co-presença. Muitas das comunidades atuais estão (ou são) desterritorializadas, não requerem a co-presença, podendo ser, inclusive, virtuais.

Em quarto lugar, a velha comunidade era o reino do Uno e somente se podia pertencer a ela; em troca, as novas comunidades são plurais: os indivíduos podem aderir a muitas delas ao mesmo tempo, entrar e sair, porque assim o desejam ou porque são expulsos. Os indivíduos desenvolvem e encenam apenas parte do que são e cada uma das partes pressupóe uma pluralidade de requisitos normativos perante os quais devem desempenhar-se $\mathrm{s}^{23}$.

Para concluir estas comparações: as velhas comunidades constituíam uma totalidade orgânica; aliás, tratava-se de um todo sem maiores divisões interiores. As novas comunidades estabelecem um arquipélago de partes sem todo, sem borda exterior, sem continente. A sociedade, como realidade e como conceito, parece perder a capacidade de construir esse todo, que alguma vez foi, no qual essa pluralidade de comunidades explodidas pudesse estar incluída.

\section{Conclusões: globalização, comunidade, educação}

O velho espaço do social estatal-nacional experimenta desde há umas três décadas uma forte corrosão em seus fundamentos. Globalização e comunidade estão na base desta transformação. Neste contexto, não é por acaso que os diversos dispositivos que desempenharam, em sua época, um papel fundamental no processo da "invenção do social" estejam atravessando uma profunda crise, das quais se devem destacar as mudanças recentes que vivem os sistemas educacionais nacionais. Para concluir este trabalho, serão apresentadas algumas reflexōes (tentativas, fragmentárias) do papel que desempenham neste processo globalização e comunidade ${ }^{24}$.

Os Estados assumiram uma tarefa ativa e estratégica na hora de instituir seus sistemas educacionais nacionais. Em muitos casos (com variações interessantes conforme os países) privilegiou-se um formato que consistiu numa autoridade educacional centralizada, relações hierárquicas normativamente reguladas entre os diferentes estamentos do sistema, a burocratização como modalidade organizacional predominante e uma orientação político-ideológica eminentemente moralizadora das populações.

23. Talvez Deleuze (1995) tenha feito referência a isto com seus conceitos de "divíduo" e "modulação".

24. Em de Marinis e Graizer (2004) apresentaram-se alguns destes argumentos, num trabalho orientado à discussão das reformas educacionais na Argentina dos anos 1990, porém, suas conclusões podem ser estendidas para outras latitudes. 
Os sistemas educacionais foram constituídos, em geral, como uma pirâmide hierárquica. $\mathrm{Na}$ cúpula, uma autoridade educacional nacional ocupou o lugar de fábrica principal de governabilidade, traçando as margens de atuação para todo o sistema. Nos estratos médios, uma série de instâncias de poder regionais e locais, inspetores, etc., com suas relações recíprocas com os atores superiores e inferiores, normativamente pautadas, estandardizadas, burocratizadas. Na base, as escolas, com seus docentes e alunos, ofereciam o ponto de contato do sistema com as populaçôes.

Em alguns países como Argentina, onde a diversidade sociocultural das populações foi importante, mas também em outros lugares com conformaçōes étnicas diferentes, os sistemas educacionais assumiram desde seu início uma missão civilizadora e normatizadora. Dessa forma, impulsionaram alguns mecanismos que em alguns casos tiveram bastante eficácia, principalmente os orientados a alcançar a integração social e nacional, impulsionando a mobilidade social ascendente, transmitindo uma língua e alguns símbolos fundamentais de nacionalidade. Puderam, assim, constituir-se como dispositivos universalistas de produção do social, de homogeneização e aplainamento de diferenças sociais e culturais, de disciplinamento do corpo individual e de regulação das populações, de uniformização de modos de vida, de distribuição massiva de competências e saberes relevantes para a vida coletiva. Esse esquema piramidal manteve sua vigência por longo tempo, apesar das numerosas transformações ocorridas.

A partir dos anos 1980 e particularmente desde os anos 1990, em diversos países latino-americanos disparou-se uma série de reformas dos sistemas educacionais, as quais colheram uma diversidade de impulsos e influências, entre eles as críticas vindas de perspectivas ideológicas muito distintas que previamente foram descarregadas sobre os sistemas. Tais críticas incluíram desde denúncias contra a marca autoritária do sistema educacional, realizadas por setores de esquerda e progressistas, até preocupações estritamente orçamentárias, animadas pela mera necessidade de reduzir o gasto público ${ }^{25}$. Em qualquer caso, as reformas conseguiram instalar um novo cenário no qual ainda hoje nos encontramos. Várias das tendências fundacionais dos sistemas educacionais foram questionadas pelas reformas; em outros aspectos, embora não pareça, houve enormes continuidades.

Para só mencionar algumas daquelas críticas: rechaço das escolas a seu ambiente comunitário mais próximo; caráter velho dos conteúdos curriculares e

25. A apropriação em código neoliberal das críticas ao sistema educacional provenientes da esquerda está muito bem tematizada por da Silva (1995). Também por Rose (1997), embora em um campo muito mais amplo do que o educacional. 
das metodologias de ensino; desprofissionalização do trabalho docente; rigidez burocrática; excessiva centralização das decisões; escassez de informação confiável sobre o funcionamento do sistema; escassa incorporação das novas tecnologias pela escola; homogeneização aplainadora de diferenças; ausência de vinculação com o mundo do trabalho; etc. As reformas, por sua vez, orientaram-se por defrontar todos esses problemas de uma vez, conseguindo impor nas mentalidades dos atores uma espécie de novo senso comum educacional, construído em torno de um punhado de novas palavras-chave: descentralização, flexibilidade, abertura à comunidade, democratização, profissionalização, accountability, gestão, diversidade, etc. ${ }^{26}$.

Não se pretende avaliar aqui o impacto destas reformas. Apenas se pretende conectar os temas educacionais desta seção do artigo com os temas teóricosociológicos que foram apresentados nas seções anteriores (desconversão do social-estatal nacional, globalização e comunidade). Isto será apresentado na forma de argumentos que pretendem sugerir, modestamente, algumas possíveis discussóes para a agenda do debate teórico e da pesquisa empírica em educação ${ }^{27}$.

Partir-se-á da seguinte pergunta: se os sistemas educacionais foram constituídos em uma época de auge do que chamamos aqui o social estatal-nacional, o que pode ocorrer com esses sistemas na atualidade, quando esta configuração se desconverte, confrontada de cima e de baixo pela globalização e pela reinvenção da comunidade?

1) Muito longe de haver se retirado, o Estado nacional cumpriu um ativo papel no desenho e na implementação das reformas dos sistemas educacionais, tão importante como o que havia desempenhado nos tempos de sua fundação. Parafraseando outra vez Santos, o Estado foi um ator preponderante na desregulação de seus próprios mecanismos de regulação da educaçãa. Um bom exemplo disso são os processos de descentralização dos serviços educacionais das instâncias estado-nacionais para as instâncias inferiores, processos que foram realizados em geral de cima, e não como resposta a demandas ou exigências de baixo. Existem diferentes tipos de descentralização, animados por propósitos também diferentes. Uma coisa é uma descentralização que empodera ${ }^{28}$

26. Não é casual que sejam estas mesmas palavras que desembarcaram em campos muito distintos do educacional. Tampouco é casual que se trate de palavras que têm ressonâncias em geral positivas, com as quais dificilmente se pode estar em desacordo.

27. Não se pretende que os temas sejam novos, embora talvez possam sê-los os pressupostos teóricos dos quais se parte aqui.

28. O termo não é muito feliz, mas aqui se utiliza porque faz parte da discursividade educacional vigente, na forma de uma tradução literal do verbo inglês to empower ou do substantivo empowerment. Algumas reflexões interessantes sobre o conceito de empowerment podem ser lidas em Cruikshank (1996). 
efetivamente as instâncias inferiores e outra, bem diferente, é um processo de delegação e transferência (conservando, por sua vez, importantes instrumentos de poder nas instâncias centrais), sem contemplar de forma acabada a disponibilidade de recursos que tornem viável a descentralização, mantendo níveis adequados de financiamento e qualidade dos serviços.

2) Para além desses processos de delegação e transferência aparente de poder, o Estado ocupa ainda um lugar relevante em questóes de educação, sem anular nem tampouco minimizar seu poder, mas reconfigurando-se diante de novas formas, definíveis por meio de palavras-chave como pluralização de atores de governo e economização de meios de governo ${ }^{29}$.

3) Com efeito, pluralização indica que, junto aos tradicionais atores estatais-nacionais, aparecem outros atores não necessariamente novos, porém que até então não tinham estado diretamente implicados no governo da educação. Além disso, isto significa que os velhos atores têm necessariamente que redefinir suas tarefas em relação àqueles. De outro lado, economização, que anda de mão dada com pluralização, significa que o Estado deixa de investir, compartilha, delega, transfere porçôes de seu poder, conservando-o em alguns meios estratégicos. Este processo, chamado por alguns autores como recentralização, longe de habilitar os níveis locais para o exercício autônomo de seu próprio governo, em geral terminou por reforçar a modalidade de controle e governo centralizador previamente existente (Tiramonti, 1988).

4) Em qualquer caso, o velho esquema piramidal do sistema educacional cambaleia porque supunha um ator estatal unificado, onipresente, massivo e coerente. Agora, no governo da educação intervém um complexo conglomerado integrado (como sempre) por elementos da burocracia estatal, porém também por muitos outros atores ${ }^{30}$.

5) Em lugar de destaque entre esses atores, poderiam ser mencionados diversos organismos internacionais, tanto de caráter financeiro (por exemplo, o BID), como os vinculados ao sistema Nações Unidas (como o PNUD). Eles têm tido crescente intervenção em questôes educacionais, seja por meio de empréstimos, seja por meio da assistência técnica que costuma acompanhá-los. Isso conecta estreitamente os temas educacionais (que até há relativamente pouco tempo constituíam questôes de política interior) aos fenômenos vinculados à globalização que foram discutidos anteriormente.

29. Esses conceitos foram tomados de diversos trabalhos que pertencem à perspectiva teórica dos governmentality studies, a qual já foi mencionada mais acima (ver nota 16).

30. A questão da diversificação de atores nos âmbitos que Bernstein (1998) definiu como "campo de recontextualização oficial" e "campo de recontextualização pedagógico" foi retomada em diversos trabalhos de Graizer (por exemplo, 2003 e no prelo). 
6) Também adquiriram um novo papel as universidades públicas e privadas que nos últimos anos se envolveram, de maneira mais marcante que antes, em diferentes tarefas vinculadas ao desenho e à implementação da reforma educacional (reconversão e capacitação docente, organização de "ciclos de complementação curricular", etc.), assim como na elaboração de estudos diagnósticos.

7) Também é importante o lugar que alguns think tanks e fundaçôes vêm ocupando. Eles têm colaborado não apenas com os conhecimentos produzidos em suas pesquisas, mas também com seus próprios quadros técnico-políticos, analistas simbólicos e consultores, para integrar-se diretamente tanto nos gabinetes educacionais como em outras áreas de governo ${ }^{31}$.

8) Um papel significativo desempenharam as empresas editoriais de livros de texto e de outros materiais escolares, chegando inclusive a influir de maneira indireta na definição de conteúdos curriculares oficiais.

9) Os mencionados processos de descentralização e a implementação das reformas em níveis estaduais e municipais outorgaram um renovado papel às respectivas direções políticas.

10) Em suma, assistimos à constituição de um novo diagrama de poder no que diz respeito às questões educacionais, com uma pluralização de atores intervenientes para dentro do sistema, com uma forte ingerência externa de fora dele, porém dentro do espaço nacional, e também, inclusive, de fora do próprio espaço nacional. $\mathrm{O}$ cenário educacional, anteriormente ocupado de modo quase excludente por docentes, pedagogos e burocratas ministeriais, começou a encher-se aos poucos de figuras que até não muito tempo eram consideradas extra-educacionais: economistas e consultores, dirigentes políticos, agentes do mercado, funcionários internacionais, etc.

11) Dito de maneira sucinta, sob o velho diagrama de poder, o Estado não atendia à demanda educacional da sociedade, mas simplesmente encarregavase de administrar a oferta, definindo de cima abaixo em que devia consistir e a quem e de que forma devia alcançar ${ }^{32}$. O correlato de suas intervençóes era em maior ou menor grau uma sociedade de cidadãos, que se pretendia homogênea $\mathrm{e}$ unificada, embora nunca o tenha sido de todo. Em qualquer caso, a marca ou a orientação dominante dessas intervenções estatais em educação era decididamente homogeneizante e normatizante.

31. Devido a isso, boa parte das equipes dirigentes da educação argentina dos últimos anos procede destes espaços, inclusive o atual Ministro de Educação da Nação. Uma caracterização geral dos perfis do "analista simbólico" como uma personificação possível da relação entre conhecimento e política pode ser encontrada, entre outros no pioneiro trabalho de Reich (1993). Vejam-se também as reelaborações que realizaram, entre outros, Aronson (200I), Braslavsky/Cosse (1996), Brunner (1993), Tenti Fanfani (1994), Camou (1997), Centeno/Silva (1998).

32. Isso, independentemente da importância da educação de gestão privada que em diferentes países teve grande peso desde muito antes que esses processos aqui descritos tivessem lugar. 
12) Em contraste, no esquema de poder emergente, o Estado deixou de ter como correlato uma sociedade homogênea, ou seja, aquele velho espaço social que outrora esteve mais ou menos unificado e soldado por um conjunto de significações simbólicas mais ou menos compartilhadas por diversos grupos sociais, cujo próprio sistema tinha a missão de difundir e inculcar. Com o que o Estado se defronta agora é uma sociedade polarizada, fragmentada, atravessada por fraturas de difícil recomposição. Esses diversos fragmentos nos quais ficou dividida a experiência vital recebem amiúde o nome de comunidades, ou assim se identificam eles mesmos na hora de perfilar suas identidades e de estabelecer suas demandas (também as educacionais).

13) Dadas as crescentes diferenças de posse de capital econômico, social, cultural e simbólico que cada comunidade pôde acumular previamente, junto com a noção de sociedade, destroça-se inclusive a própria noção de sistema educacional. Em um sentido raso e convencional, sistema remete a um todo com partes integradas, reciprocamente interdependentes e interpenetradas. Porém, atualmente, parecem perfilar-se antes uma série de circuitos educacionais fortemente diferenciados, com diferentes velocidades e qualidades que dificilmente se consolidam em um único sistema, integrado e unificado, embora, ao menos em um sentido formal, este continue existindo.

14) Mesmo diante da evidência crescentemente consolidada da existência desses circuitos educacionais heterogêneos e incomensuráveis, o Estado continua sustentando um discurso homogeneizador e nivelador de condiçôes sociais. Não se conhece Estado no mundo que possa renunciar a fazê-lo, ao menos abertamente. Entretanto, parece orientar suas preocupações prioritárias àqueles que vivem em comunidades que ocupam espaços periféricos de sociabilidade, para aqueles que não podem enfrentar por si mesmos suas próprias opções, escolhendo no mercado o que consideram mais adequado, tendo em vista o que percebem como um futuro crescentemente competitivo, no qual deverão viver seus filhos e para o que - a seus olhos -parece imperioso municiar-se.

15) Isto que aqui se está postulando em referência estrita a questôes educacionais poderia perfeitamente ser transportado para outros campos da experiência vital atual dos indivíduos e suas famílias, para os quais (tanto ou mais do que para o campo educacional) os bens ou serviços, que anteriormente tinham caráter social ou eram providos de maneira pública, mercantilizaram-se de modo significativo. Mesmo assim, algumas comunidades podem encontrar no mercado aquilo que usam para satisfazer suas necessidades; um mercado que, além disso, revelou-se muito flexível na diversificação de suas ofertas, graças a um marketing refinado que consegue identificar claramente os diversos nichos de consumidores ou clientes. 
16) Na época em que os mecanismos de integração social (também os que o próprio campo educacional mobilizava) conservavam ainda certa vigência, várias perspectivas críticas haviam-nos denunciado, fazendo referência a seu caráter autoritário, aplainador irrestrito das diferenças. Além disso, também se questionava que, por trás desse aparente igualitarismo sociocultural, o que havia na realidade eram alguns mecanismos de opressão e de promoção do conformismo e da apatia. Apoiando-se em parte naquelas críticas, emergiram posteriormente palavras de ordem tais como atenção à diversidade, um slogan que circulou profusamente nos últimos tempos no debate educacional e com o qual, em princípio, como com tantos outros termos que circulam hoje, não custa nenhum esforço simpatizar.

17) Tais tipos de palavras de ordem são interessantes para a análise porque estão atravessadas por profundas ambivalências. De um lado, na mesma linha que haviam esboçado anos antes as perspectivas críticas e contratuais do sistema educacional, palavras de ordem dessa natureza podem implicar uma posição decididamente emancipatória, impulsionada justamente pelas reivindicações particularistas de certas comunidades que exigem sejam atendidos de maneira específica seus direitos também específicos, respeitando suas culturas, suas tradições, suas necessidades. Porém, também podem ter como resultado prático a contenção, o encurralamento de certas outras (ou das mesmas) comunidades em espaços periféricos e degradados de sociabilidade, longe de qualquer noção que implique um registro substantivo de cidadania, como quer que seja definida.

18) Dessa forma, assistimos a uma forte tensão entre demandas de sinais contrapostos. De um lado, diversos atores sociais e políticos continuam apresentando suas reivindicações de um tratamento igual para populações desiguais e o fazem invocando e partindo de uma noção universalista de alguns direitos de cidadania social que, de sua perspectiva, devem necessariamente ser garantidos pelo Estado. Por outro, aparece outro tipo de posições para as quais o que se exige é um tratamento desigual para populaçóes desiguais. Neste caso, o panorama é muito mais difícil de caracterizar porque engloba posiçóes bem diferentes que pouco ou nada podem ter em comum: de um lado, estão aqueles que sustentam posições particularistas de defesa dos direitos de uma cidadania diferenciada (tal é o caso, por exemplo, de certas comunidades e movimentos sociais). Porém, também esta posição pode muito bem ser sustentada por posiçôes abertamente favoráveis a soluções de mercado, ou seja, posições pelas quais se pretende reconverter os direitos de cidadania em direitos particulares de um determinado tipo de consumidores ou clientes que defendem com unhas e dentes a liberdade de escolha que é restringida pela prepotência estatal. 
19) Isso projeta fortes dilemas, quase uma armadilha, para aqueles que pretendem sustentar posiçóes críticas e emancipatórias, embora convenientemente remoçadas para afrontar as problemáticas do presente. Por isso, é necessário advertir que qualquer das perspectivas esboçadas no ponto anterior encerra graves perigos. A reivindicação irrestrita da igualdade poderia conduzir a um aplainamento autoritário das diferenças culturais, como aquela que de fato conduziu no passado à tendência homogeneizadora do sistema educacional e que foi por isso, em seu momento, justamente criticada. De outro lado, a veemente reivindicação da diferença poderia conduzir também a uma situação de caráter marcadamente anômico e anti-solidário, terreno mais que propício para que se desatem tendências à sobrevivência do mais apto, posto que nem todas as comunidades se encontram nas mesmas condiçôes de formular demandas ao Estado e de fazê-las valer ou de satisfazer autonomamente suas próprias necessidades. Como fazer, nesse contexto, para imaginar um mundo onde possamos ter "direito a ser iguais cada vez que a diferença nos inferioriza" 33 ?

20) Comunidade e globalização não são em si mesmas palavras inocentes, porém, nem por isso deveriam ser demonizadas ou louvadas de maneira incondicional. Trata-se de fenômenos produzidos, impulsionados por racionalidades políticas variadas. Os diversos grupos sociais lutam por impor-lhes determinada conotação diante de outras possíveis e por dar-lhes determinada orientação. Por isso, a direção que todas essas tendências possam tomar está, em princípio, aberta à extrema contingência das lutas sociais.

21) Sem hastear pretensões iluministas ou vanguardistas, talvez seja a imaginação sociológica um apoio importante para a caracterização do cenário atual e também um relevante estímulo para uma imaginação política mormente empobrecida e degradada para a tarefa, de curto prazo, de tapar buracos. Uma imaginação política que, mais que a nostálgica reabilitação dos tempos irremediavelmente perdidos (como lamentavelmente acontece em boa parte do campo crítico do neoliberalismo), poderia assumir o desafio de imaginar novos espaços-tempos para contribuir com a reinvenção da cidadania, da democracia, da comunidade e da emancipação.

(Buenos Aires, julho de 2007)

\section{Referências bibliográicas}

ARONSON, Perla. El "Saber" y las "Destrezas". Perfil de los graduados universitarios. In: NAISHTAT, Francisco; GARCÍA RAGGIO, Ana María; VILLAVICENCIO, Susana (Ed.). Filosofias de la universidad. Conflicto de racionalidades. Buenos Aires: Colihue, 2001a. p. 131-145.

33. As frases entre aspas pertencem a Santos (apud de Marinis, 2005c, p. I I 
BASIL, Bernstein. Pedagogía, control simbólico e identidad. Madrid: Morata, 1998.

BAUMAN, Zygmunt. Trabajo, consumismo y nuevos pobres. Barcelona: Gedisa, 2000.

. Comunidad. En busca de seguridad en un mundo hostil. Madrid: Siglo XXI, 2003.

BRASLAVSKY, Cecilia; COSSE, Cosse, Gustavo. Las actuales reformas educativas en América Latina: Cuatro actores, tres lógicas y ocho tensiones. Informe - PREAL, Buenos Aires, n. 5, 1996.

BRUNNER, José Joaquín. Investigación social y decisiones políticas. Sociedad — Revista da Faculdade de Ciencias Sociales da Universidade de Buenos Aires, Argentina, n. 3, p. 31-43, 1993.

CAMOU, Antonio. Los consejeros del príncipe. Saber técnico y política en los procesos de reforma económica en América Latina. Nueva Sociedad, Caracas, Venezuela, n. 152, p. 54-67, 1997.

CASTEL, Robert. Las metamorfosis de la cuestión social. Una crónica del salariado. Buenos Aires: Paidós, 1997.

. La inseguridad social. ¿Qué es estar protegido?. Buenos Aires: Manantial, 2004.

CENTENO, Miguel Angel; SILVA, Patricio (Ed.). The politics of expertise in Latin America. Londres: Macmillan Press, 1998.

CRUIKSHANK, Barbara: Revolutions within: self-government and self-esteem. In: BARRY, Andrew; OSBORNE, Thomas; ROSE, Nikolas (Ed.). Foucault and political reason. Liberalism, neo-liberalism and rationalities of government. Londres: UCL Press, 1996. p. 231-251.

DEAN, Mittchel. Governmentality. Power and rule in modern society. Londres: Sage, 1999.

DELEUZE, Gilles. Post-scriptum sobre las sociedades del control. In: DELEUZE, Gilles. Conversaciones 1972-1990. Valencia: Pre-Textos, 1995. p. 277-286.

DE MARINIS, Pablo. Gobierno, gubernamentalidad, Foucault y los anglofoucaultianos (Un ensayo sobre la racionalidad política del neoliberalismo). In: RAMOSTORRE, Ramón; GARCÍA SELGAS, Fernando (Ed.). Globalización, riesgo, reflexividad. Tres temas de la teoría social contemporánea. Madrid: Centro de Investigaciones Sociológicas, 1999. p. 73-103.

Überwachen und Ausschließen. Machtinterventionen in urbanen Räumen der Kontrollgesellschaft. Pfaffenweiler: Centaurus- Verlagsgesellschaft, 2000.

. 16 comentarios sobre la(s) sociología(s) y la(s) comunidad(es). Papeles del CEIC Centro de Estudios sobre la Identidad Colectiva (CEIC), Universidad del País Vasco, España, n. 15, enero, 2005. Disponível em: <http:/www.ehu.es/CEIC/Papeles/15.pdf>.

. De la sociedad disciplinaria a la sociedad de control. Inter-Criminis, México, n. 13, p. 147-195, Segunda Época, abr.-jun. 2005.

- Cada país tiene su Tercer Mundo (comentario acerca de la obra de Boaventura de Sousa Santos). N. — Revista de Cultura de Clarín, n. 84, p. 10-11, 7 de mayo, 2005.

. Sociología de los derechos humanos ("Guía de Estudios" para la "Maestría en Derechos

Humanos y Democracia” de la FLACSO-México), nov. 2006. (57 páginas). (Material 
mimeografado, aceito para publicação em forma de livro, que será editado por FLACSO em 2008).

DE MARINIS, Pablo; GRAIZER, Oscar. Tecnologías de gobierno de la educación y recontextualizaciones locales (un ensayo de sociología de la transformación educativa). In: CONFERENCIA INTERNACIONAL DE SOCIOLOGÍA DE LA EDUCACIÓN (ISA), 25-28 agosto, 2004, Buenos Aires.

DONZELOT, Jacques. La invención de lo social. Ensayo sobre la declinación de las pasiones políticas. Buenos Aires: Nueva Visión, 2007.

FOUCAULT, Michel. Vigilar y castigar. Nacimiento de la prisión. México: Siglo XXI, 1976. . Historia de la sexualidad. Tomo I. México: Siglo XXI, 1987. Tomo I.

. Las redes del poder. In: FOUCAULT, Michel. Las redes del poder. Buenos Aires: Almagesto, 1996. p. 49-72.

. Defender la sociedad. Curso en el Collège de France (1975-1976). Buenos Aires: Fondo de Cultura Económica, 2000.

. Seguridad, territorio, población. Curso en el Collège de France (1977-1978). Buenos Aires: Fondo de Cultura Económica, 2006.

GIDDENS, Anthony. Consecuencias de la modernidad. Madrid: Alianza Editorial, 1993.

GUDYNAS, Eduardo. Geografías fragmentadas: sitios globalizados, áreas relegadas. Revista del Sur, n. 160, p. 3-13, abr.-jun. 2005.

GRAIZER, Oscar. Crítica a la formación basada en competencias. Universitat de València, Facultad de Filosofía y Ciencias de la Educación, 2003. . "Evaluación y gobierno de la educación". (No prelo).

IANNI, Octavio. Teorías de la globalización. México: Siglo XXI, 1996. . La sociedad global. México: Siglo XXI, 1998.

LANDER, Edgardo. La utopía del mercado total y el poder imperial. Revista Venezolana de Economía y Ciencias Sociales, v. 8, n. 2, p. 51-79, mayo-agosto 2002.

MAFFESOLI, Michel. El tiempo de las tribus. El declive del individualismo en las sociedades de masas. Barcelona: Icaria Editorial, 1990.

MARX, Karl; ENGELS, Friedrich.: Manifiesto del Partido Comunista. Buenos Aires:, Editorial Anteo, 1985.

NISBET, Robert. La formación del pensamiento sociológico 1. Buenos Aires: Amorrortu, 1996. V. 1.

O'MALLEY, Pat. Risk and responsibility. In: BARRY, Andrew; OSBORNE, Thomas; ROSE, Nikolas (Ed.). Foucault and political reason. Liberalism, neo-liberalism and rationalities of government. Londres: UCL Press, 1996. p. 189-207.

QUIJANO, Aníbal: Colonialidad del poder, globalización y democracia. Lima, dic., 2000. Disponível em: <http://www.rrojasdatabank.info/pfpc/quijan02.pdf>. Acesso em: 16 agosto 2006. 
RAMÍREZ, Francisco e BOLI, John. La construcción política de la escolarización de masas. In: FERNÁNDEZ ENGUITA, Mariano (Ed.). Sociología de la Educación. Barcelona: Ariel, 1999.

REICH, Robert. El trabajo de las naciones. Hacia el capitalismo del siglo XXI. Buenos Aires: Vergara Editores, 1993.

ROSE, Nikolas. The death of the social? Re-figuring the territory of government. Economy and Society, v. 25, n.3, p. 327-356, 1996.

. El gobierno en las democracias liberales “avanzadas": del liberalismo al neoliberalismo. Archipiélago, v. 29, p. 25-40, 1997.

1999.

. Powers of freedom. Reframing political thought. Cambridge University Press: Cambridge,

SANTOS, Boaventura de Sousa. La caída del Ángelus Novus: ensayos para una nueva teoría social y una nueva práctica política. Bogotá: ILSA, 2003.

. Reinventar la democracia. Reinventar el Estado. Buenos Aires: CLACSO, 2005.

SILVA, Tomaz Tadeu da: El proyecto educacional moderno ¿identidad terminal?. Propuesta Educativa, n. 13, p. 5-10, dic. 1995.

SVAMPA, Maristella: Los que ganaron. La vida en los countries y barrios privados. Buenos Aires: Biblos, 2001.

TENTI FANFANI, Emilio: Del Intelectual intelectual Orgánico orgánico al Analista analista Simbólicosimbólico. Revista de Ciencias Sociales — Universidad Nacional de Quilmes, n. 1, 1994.

TIRAMONTI, Guillermina: Reestructuración del sistema educativo argentino en la tensión del cambio y la permanencia de las tradiciones políticas. Sociedad - Revista da Faculdade de Ciencias Sociales da Universidade de Buenos Aires, Argentina, n. 12/13, p. 103-126, 1998.

Recebido em 28 de março de 2008 e aprovado em 13 de junho de 2008. 